\title{
DAVID LODGE Y EL LENGUAJE DEL HUMOR
}

\author{
Rosa Lorés* \\ Universidad de Salford
}

\begin{abstract}
RESUMEN. Este artículo intenta establecer las bases de análisis del lenguaje humorístico de tal forma que su traducción a otra lengua resulte más satisfactoria. Para ello nos hemos basado en los postulados que el crítico Walter Nash establece sobre el lenguaje del humor aplicándolos directamente sobre un corpus extraído de la novela Changing Places de David Lodge.

ABSTRACT. The purpose of this article is to establish an analytical framework which allows the translator to carry out his task in a more satisfactory way when dealing with the language of humour. In order to fulfill our purpose we have based our study in Walter Nash's modes of humouristic expansion, three dimensions which have been applied to a base of exemplification taken from David Lodge's Changing Places.
\end{abstract}

¿Qué nos hace sonreir al leer un texto? ¿Qué hace que una respuesta, una reacción, una frase, un episodio resulten graciosos? ¿Qué hace que califiquemos un texto de humorístico? ¿Es sólo la situación narrada o hay algo más? Parece claro que el dispositivo del humor se dispara no sólo por el episodio en sí, más o menos gracioso, más o menos ridículo, sino también por el uso que se hace del lenguaje, de la sintaxis, de la semántica, de los sonidos.

Para que un texto resulte humorístico debe existir un área de creencias y de actitudes sociales y culturales, área compartida por emisor y receptor, y, en el caso del texto escrito, por autor y lector. Sobre esta base común el humor echa raíces. Es un punto de partida, una base imprescindible sobre la que el lenguaje despliega sus numerosos recursos convirtiéndose en el factor determinante en la producción de textos humorísticos.

* Licenciada en Filología Inglesa por la Universidad de Zaragoza. Departamento de Inglés de la Escuela Oficial de Idiomas $n^{01}$ de Zaragoza. c/ Miguel Servet 34-36, P.4, A, 4ºB. 50008 Zaragoza. 
Walter Nash, en The Language of Humour, distingue tres tipos o "modos" de "expansión humorística", y cito textualmente:

Generic refers to such elements ... of a 'genus' or genre, not only of literary forms and conventions, but also of cultural facts. Linguistic obviously alludes to the patternings of syntax, semantics, and sound, while interactional stands for the relationship of executant and respondent (comedian/audience, writer/reader, Character A/Character B) and the suppositions and entailments that are the pragmatic or logical basis of their relationship. ${ }^{1}$

Estos tres "modos" no pueden ser considerados como excluyentes sino como interdependientes, la actuación de uno modifica y modela la actuación del otro resultando de ello una compleja red de interacciones que hace muy difícil la tarea de aislar los mecanismos activados en un texto considerado humorístico.

$\mathrm{Y}$ es precisamente la frustación que se siente al comparar traducciones con versiones originales de textos humorísticos lo que apunta hacia la idea de interdependencia e interacción: ¿por qué un texto escrito en inglés provoca sin esfuerzo una sonrisa en el lector mientras que su versión traducida al español lucha penosamente intentando provocar el mismo efecto?

Sin duda el humor es un hecho cultural y, como tal, depende del lenguaje, que es a su vez la máxima expresión de la cultura. Además, como hecho cultural y, por lo tanto, social, el humor apunta al aspecto pragmático del lenguaje, al lenguaje como acción comunicativa. Los tres modos o tipos anteriormente señalados por Nash (genérico, lingüístico e interaccional) forman parte de una compleja red de relaciones e interacciones que difícilmente pueden ser aisladas para ser analizadas. Por tanto, ¿debemos extrañarnos de la dificultad que entraña la traducción de tales textos y de los resultados tan poco satisfactorios?

Durante los últimos años, los estudiosos de la traducción han señalado la equivalencia funcional, o equivalencia de efecto, como el objetivo perseguido por los traductores en su trabajo. Este es el caso, más si cabe, de textos cuyo valor reside en el efecto tan preciso y concreto que intentan producir en el lector, la sonrisa. En estos casos, y cuando el mismo efecto no se produce, el texto pierde su valor como tal, ya que se modifica el proceso comunicativo concebido por el autor.

Los tres modos de expansión humorística señalados por Nash se pueden considerar en relación directa con tres dimensiones que, de forma conjunta, activan los diferentes dispositivos y recursos del humor. Son la dimensión cultural (básica en el 'generic mode'), la dimensión lingüística (en el 'linguistic mode') y la pragmática (en el 'interactional mode').

Y son estas tres dimensiones y la forma en que se relacionan las que dificultan la consecución de la equivalencia funcional en la traducción de textos humorísticos.

1. W. Nash (1985: 21-22) 
Analicemos un proceso de traducción: un autor escribe un texto dirigido a un receptor que comparte con él no sólo una determinada lengua sino también una determinada cultura, es decir, un complejo mundo de creencias, expectativas, costumbres, experiencias colectivas, todo un modo de vida, en definitiva. El traductor asume la tarea de dirigir ese texto a un lector diferente, que no comparte con el autor original ni la lengua ni la cultura. Para ello, el traductor reescribe el texto utilizando un código diferente, la lengua del que va a ser su lector. Pero para que el efecto que este segundo texto produzca sea equivalente al provocado por el primero, el traductor debe enmarcar el tex to en un código cultural también diferente, el del lector hacia el que la traducción se dirige. El error más común en la traducción parece residir en la utilización de un código lingüístico diferente sin que éste se enmarque en un código cultural también diferente. Y este error se puede hacer extensible no sólo a la traducción del texto humorístico sino a todos los procesos de traducción en general. Durante el proceso de la traducción el texto se descontextualiza y pasa a ser considerado como un repertorio finito de signos lingüísticos diferentes.

Parece ser que los resultados poco satisfactorios producidos por la descontextualización en el proceso de traducción son todavía más patentes en textos humorísticos. Y quizá una razón para ello sea, no el hecho de que exista una dimensión cultural (dimensión existente en mayor o menor grado en todo texto), sino que dicha dimensión cultural sea un elemento difícilmente aislable cuya actuación modifica y modela las acciones de otras dimensiones, que a su vez diseñan las actuación de aquélla.

La novela Changing Places del autor británico David Lodge nos servirá como base de ejemplificación. Changing Places fue publicada por primera vez en 1975 en Londres por la editorial Penguin. Su primera traducción al español fue publicada por la editorial Noguer (Barcelona, 1977) bajo el título Tu marido y mi mujer, y fue realizada por Vicente Riera Llorca. Dicha traducción ha sido reeditada por Versal (Barcelona, 1990) bajo el título de Intercambios.

Destacaremos algunos aspectos culturales, lingüísticos y pragmáticos que no han sido tenidos en cuenta por el traductor a la hora de realizar su tarea y que contribuyen, quizá no individualmente, pero sí de forma conjunta, a que la versión española pierda la frescura, la agudeza y el ingenio del original. No se trata de un inventario exhaustivo sino de unas breves notas muy revelativas a la hora de establecer los niveles en los que se realizan los procesos traductivos.

Empezaremos este breve análisis destacando algunos aspectos que podrían ser englobados dentro de una dimensión cultural. Son elementos que pueden ser considerados como hechos culturales, hechos de los que el autor se sirve para provocar la sonrisa en el lector. Si un lector distinto como es el español desconoce cuál es el referente, el juego humorístico se rompe. La labor del traductor reside en estos casos en acercar el lector español a un mundo cultural diferente, el británico, mediante diversos mecanismos que van desde la utilización de equivalentes culturales a la expansión o a la paráfrasis.

Analicemos algunos ejemplos:

Las referencias literarias son muy numerosas en Changing Places. De hecho, una 
de ellas conforma el subtítulo: A tale of two campuses. Significativamente, dicha referencia ha sido omitida en la versión española. Quizá el traductor ha considerado que el lector medio español, a quien se dirige la traducción, no relacionaría el subtítulo con la novela de Dickens. Podemos pensar que esta decisión participa de una tendencia generalizada a subestimar las capacidades del lector para descodificar el mensaje. "A tale of two campuses" podría haber sido traducido como "Historia de dos universidades", parafraseando Historia de dos ciudades, que el lector hubiese reconocido sin mayor dificultad.

Son comunes, asimismo, las referencias a los medios de comunicación, bien sea a programas o personajes televisivos. Si la intención del autor al utilizar estas referencias es la de contribuir al tono humorístico del texto, el traductor, como intérprete y mediador que es entre entre éste y el lector de la versión traducida, deberá desplegar todos los medios a su alcance para provocar una reacción en su propio receptor equivalente a la producida en el lector del texto original.

Comparemos algunos pasajes de la novela:

-'What is it you want to watch, Bernadette, "Top of the Pops"?

-' Er, no, not exactly, Mr. Zapp,' said O'Shea. 'The BBC 2 has a documentary on the Little Sisters of Misery and Bernadette has an aunt in the Order.' (pg.91)

-'¿Qué es lo que quieres ver, Bernadette? ¿El Top of the Pops?'

$\therefore$ Mmmm...no, no exactamente eso, señor Zapp' -dijo O'Shea.

'La BBC 2 da un documental sobre las Hermanitas de los Pobres, y Bernadette tiene una tía en la orden.' (PG. 94)

El lector de Intercambios en términos generales no reconoce el "Top of the Pops" como uno de los programas musicales de mayor audiencia entre la juventud británica. La disparidad existente entre dicho programa y un programa religioso queda matizada en la versión española. En casos como estos el traductor debería recurrir a algún procedimiento que le permitiera transmitir ese contraste tan agudo. En el ejemplo que nos ocupa se podría haber realizado un simple ejercicio de expansión:"¿Qué es lo que quieres ver, Bernadette? ¿Las actuaciones musicales del Top of the Pops?" o "¿El programa musical Top of the Pops?"

Continuas referencias al mundo académico son utilizadas por el autor para crear el tono humorístico que domina en el texto. Pero los sistemas educativos británico y americano difieren en alguna medida del español. Este hecho se convierte en fuente de conflicto en numerosas ocasiones:

'No one could award a delicate mark like $B+/ B+$ ? + with such confident aim.' (pg.17)

' Nadic podía dar una nota tan delicada como $\mathrm{B}+/ \mathrm{B}+$ ?+ con tan 
seguro acierto.' (pg.23)

La nota B no significa nada para el lector español, y tanto es así que la broma se pierde. El traductor debería haber tratado de encontrar un equivalente en el sistema educativo español, por ejemplo: Notable alto/Notable alto?alto.

Además de la dimensión cultural, la dimensión lingüística confiere otro nivel de análisis en el estudio de la traducción del humor. Esta dimensión constituye una fuente de dificultad extrema para el traductor, que se encuentra con la tarea de trasladar a su propia lengua juegos de palabras, retruécanos, aliteraciones, y otras figuras retóricas donde forma y contenido se conjugan de una manera difícilmente transferible a otro código lingüístico.

Los juegos de palabras conforman uno de los recursos lingüísticos con fines humorísticos más utilizados por David Lodge en Changing Places.

Examinemos algunos ejemplos:

' I doubt if we have the same problems, Mr. Sparrow'.

-' Swallow'

-'Mr.Swallow. Sorry. A much nicer bird.'

(pg.79-80)

El juego de palabras Sparrow/Swallow no se mantiene en la traducción al español, y debe ser explicado por el traductor mediante una nota a pie de página:

-' Dudo que tengamos el mismo problema, señor Sparrow.'

-'Swallow'

-'Sr.Swallow. Perdone usted. Es un pájaro mucho más bonito.'

En inglés, Swallow: golondrina; Sparrow: gorrión (N. del T.)

¿Qué opciones se ofrecen al traductor en casos comoéstos? En cierta forma se trata de una cuestión de enfoque o, incluso, de lealtades hacia el autor del texto y su mundo lingüístico y cultural o hacia el lector de la traducción y el entorno linguiístico y cultural de éste. Mantener la forma en detrimento del contenido implica en alguna medida transmitir al lector de la traducción el sabor y las peculiaridades de un mundo cultural que le es ajeno. La utilización de notas a pie de página para explicar el contenido es una solución de compromiso adoptada por el traductor que revela cierta incapacidad por su parte para resolver el problema planteado.

Si los intereses del traductor se centran en su propio lector tenderá a la transmisión del contenido, la mayoría de las veces en detrimento de la forma, ya que no es muy frecuente el caso en que el grado de similitud entre dos lenguas le permita reproducir el juego de palabras en sus dos niveles. El traductor se halla en un proceso constante de toma de decisiones en el que múltiples y variados factores deben ser tenidos en cuenta. 
Volvamos al ejemplo que nos ocupa. Podría haberse forzado un juego de palabras en español como éste:

-' Dudo que tengamos el mismo problema, señor Periquito.'

-' Chorlito'

-' Sr.Chorlito. Perdone usted. Es un pájaro mucho más bonito.'

Periquito/Chorlito es un juego de palabras basado no solamente en su similitud fonémica sino también en la caracterización de Philip Swallow como un personaje ingenuo, que podría asociarse con la expresión española "cabeza de chorlito".

Sin embargo esta solución no puede considerarse apropiada puesto que este juego de palabras no es tan relevante como para llegar a cambiar el nombre a uno de los dos protagonistas.

Consideraciones sobre la relevancia del juego de palabras en cuestión, sobre la primacía de la forma sobre el contenido, deben ser sopesadas por el traductor a la hora de resolver este tipo de problemas.

Analicemos un ejemplo distinto:

-'What's it called, Rubbish?'

-' Rummidge'

-' I thought you said Rubbish.'

$($ pg.81)

La solución aportada por el traductor es la misma que la sugerida para el ejemplo anterior: mantener la forma y transmitir el contenido mediante una nota a pic de página:

- ‘Cómo dice que se llama? Rubbish?'

-'Rummidge'

-' Creí que había dicho Rubbish.'

En inglés, Rubbish : basura, desperdicio (N. del T.)

La relación fonémica entre Rummidge y Rubbish es evidente. En cuanto al contenido, habría que resaltar que el hablante inglés asocia "Rummidge" con la palabra "rummage", que indica la acción de buscar entre objetos viejos, abandonados, en desuso. De allí su relación por la vía del contenido con la palabra "rubbish". Teniendo esto como punto de referencia el traductor podría intentar poner en práctica algún procedimiento que le permitiera transmitir las connotaciones que envuclven el binomio Rummidge/Rubbish, y que el lector español pierde. Una posible solución consistiría en la transferencia de esa red de connotaciones por medio de una palabra española y la consiguiente "anglización" de este término. Por ejemplo, si tomamos la palabra española "escombros", connotativamente similar a la inglesa "rummage", podríamos 
someterla a un proceso de anglización de tal forma que diera como resultado el término "Scomborough". Este nuevo término permitiría al traductor establecer un juego de palabras parecido al de Rummidge/Rubbish.

Sin embargo, factores como los señalados en el ejemplo anterior deben ser sopesados. Rummidge no es un nombre imaginario más, elegido al azar por David Lodge. Es sabido que Lodge centra la acción de Changing Places en la ciudad de Birmingham. Birmingham fue durante mucho tiempo conocida por sus habitantes con el nombre de "Brummidgeham", de donde Lodge derivó el término "Rummidge". Además, no solamente Changing Places, sino otras novelas del mismo autor, tales como Nice Work, se desarrollan en Rummidge. El status que esta ciudad imaginaria ha alcanzado en la historia de la ficción británica contemporánea es un factor demasiado relevante para que el traductor no lo tenga en consideración a la hora de elegir uno u otro procedimiento.

La aliteración es otro recurso retórico enmarcado dentro de una dimensión lingüistica, cuya función en el texto viene marcada por la intencionalidad del autor. En Changing Places son numerosos los ejemplos de aliteraciones creadas por David Lodge para fomentar el tono humorístico de las novelas. Quizá el ejemplo más evidente sea el del slogan político, que busca la efectividad basada en la brevedad y en la facilidad para ser recordado, es decir, en la similitud de fonemas:

\section{KEEP KROOP \\ SWINGING SAVES FUCK DUCK}

Riera Llorca optó por la siguiente traducción del texto:

\author{
CONSERVEMOS A KROOP \\ EL RITMO ES LA SALVACION \\ JODETE A M'MON
}

(pg.53)

Claramente se percibe la fidelidad del traductor español al contenido informativo de las expresiones, obviando el recurso retórico de la aliteración y, más gravemente, la intención del autor.

Como en el caso de los juegos de palabras, cl traductor se encuentra ante la disyuntiva de preservar la forma modificando el contcnido o viceversa. El traductor debe establecer un sistema de prioridades encabezado por la necesidad de preservar la intencionalidad del autor. En segundo lugar, y sirviendo a los propósitos de la anterior, situaríamos la necesidad de mantener los recursos linguísticos que sirven a este propósito, la aliteración en este caso. A un tercer lugar quedaría relegada la necesidad de transmitir el contenido informativo de la expresión.

Este intento de sistematizar el proceso de traducción invierte el orden de los 
procedimientos seguidos por el traductor y se llega a resultados diferentes. Proponemos las siguientes traducciones, que intentan primar la intencionalidad del autor sobre los recursos lingüísticos (forma), y los recursos lingüísticos sobre el contenido informativo:

\section{CREEMOS EN KROOP EL RITMO ROMPE / BENDITO BAILE / VIVA EL BAILE DUCK KAPUT}

A pesar de este intento de establecer unas líneas para la sistematización de los procesos traductivos las soluciones siguen siendo individuales e idiosincrásicas. Las dificultades a las que se enfrenta el traductor son múltiples y siempre directamente proporcionales a la distancia existente entre las dos lenguas. Pasajes como el que sigue plantean un alto nivel de dificultad:

'...topless and bottomless ping-pong, roulette, shoe-shine, barbecue, all-in wrestling and go-go dancing.'

El traductor, una vez más, ha optado por la primacía del contenido informativo sobre los demás aspectos:

'...ping-pong, ruleta, limpicza de zapatos, barbacoa, lucha y baile a go-go entre chicas en topless o completamente desnudas.'

(pg.113)

Aún en casos como estos, en los quelas posibles soluciones resultan poco satisfactorias, el traductor en todo momento deberá centrar su punto de mira en la intencionalidad del autor, en la función del texto, y deberá desplegar mecanismos de compensación que le permitan establecer una cierta equivalencia funcional.

Las metáforas constituyen un campo de análisis a caballo entre la dimensión cultural y la dimensión lingüística. La metáfora es una expresión lingüística que revela una forma muy particular de aprehender la realidad. Por tanto, a mayor proximidad cultural, mayor facilidad de traducción, y viceversa. Teniendo en cuenta que no es nuestra intención profundizar en la problemática de la traducción de metáforas analizaremos brevemente la cuestión de la traducción de los verbos metafóricos ingleses, tan característicos de esta lengua, y que son utilizados por Lodge como un recurso lingüístico más a la hora de dotar a su novela del tono humorístico que la caracteriza. Estos verbos poseen la cualidad de comprimir una imagen en una sola palabra, mientras que la lengua española necesita utilizar más de un término para expresar esta misma imagen. Como resultado, la metáfora española, traducción de ese verbo metafórico inglés, pierde fuerza y debilita el efecto que la imagen produce en el lector del texto traducido. Veamos algunos ejemplos: 
'...on his return from ferrying O'Shea to and from Mrs. Reilly'

'...cold-shivers roller-coasting down his curved spine'

Las traducciones propuestas por Riera Llorca no sólo no consiguen reproducir las imágenes sugeridas por los verbos metafóricos ingleses sino que las omiten completamente:

'...cuando al regresar de la visita de O'Shea a la señora Reilly'

‘...sintió escalofríos'

Quizá una forma más satisfactoria de trasladar estas metáforas al español fuese utilizar un mecanismo de expansión de la imagen. Por ejemplo:

\section{Reilly" \\ "cuando al regresar de llevar y traer a O'Shea de casa de la señora \\ "sintió escalofríos subiendo y bajando por su espinazo"}

Sin embargo, y como hemos señalado anteriormente, a pesar de que estamos tratando con ejemplos aisladamente, hay que pensar que forman parte de un todo, el texto, y que es la función de este tex to en conjunto la que hay que intentar transmitir. Por tanto, la cuestión no es tanto si una expresión en concreto ha sido traducida satisfactoriamente sino si la función textual ha sido transferida. No se trata tanto de traducir aliteración por aliteración y metáfora por metáfora, sino, primeramente, de identificar la función que estos elementos desempeñan en cl tex to y, despućs intentar trasferir dicha función.

Al inicio de este artículo señalábamos la dimensión pragmática como la tercera perspectiva desde la cual el autor activa una serie de mecanismos cuyo propósito, cuya función, es contribuir al tono humorístico que predomina en el tex to que nos ocupa. La Pragmática se encarga de estudiar la relación entre las locuciones y el contex to en el que éstas se emiten. Desde Nida hasta los más recientes teóricos de la traducción, todos coinciden en establecer la equivalencia como cl objetivo del traductor, y señalan que esta equivalencia debe ser entendida en términos pragmáticos, es decir, como equivalencia de efecto. El traductor, como productor que es de textos, debe intentar reproducir en un diferente marco cultural su propia interpretación de lo que cl hablante o autor quiere decir, de tal forma que consiga provocar el efecto buscado en sus propios lectores.

Para ejemplificar las dificultades a las que el traductor debe de enfrentarse para conseguir el efecto deseado, el humor, y centrándonos en aspectos pragmáticos, analizaremos brevemente el problema de la traducción de cxclamaciones y de términos que se consideran tabú. 
Las exclamaciones, tradicionalmente consideradas como material de relleno, son quizá los elementos lingüísticos más significativos a la hora de interpretar las actitud del hablante. Hay que tener en cuenta que constituyen aspectos idiolécticos de un hablante y, como tales, su traducción a otra lengua, su encuadre en otro marco cultural, debe ser llevado a cabo de una forma extremadamente cuidadosa. Analicemos el siguiente pasaje de Changing Places:

-' Fine! Where are you staying, Mr.Swallow?'

$\therefore$ At the Faculty Club for the time being, while I look-'

-' Fine, that's fine, Mr.Swallow. You and I must have lunch together real soon.'

'Well, that would be very nice, but what I-'

-' Fine. And I while I think of it Mrs. Hogan and I are having some folks around for drinks on Sunday, 'bout five, could you make it?'

-' Well, yes, thank you very much. About my courses-'

-' Fine. That's just fine. And how are you settling in, Mr.Swallow?'

$\therefore$ Oh, fine, thanks,' said Philip mechanically. 'I mean, no, that is-' But he was too late. With a last "Fine", Hogan had rung off.'

(pg.66-7)

La reiteración en el empleo de la exclamación "Fine" constituye un rasgo idiosincrásico que caracteriza el idiolecto del Professor Hogan, interlocutor de Philip Swallow. Su personaje queda caracterizado de una forma muy precisa a través de su particular uso del lenguaje, del cual las exclamaciones son parte integral. La repetición de "Fine" es esencial, pues, para provocar un efecto humorístico en el episodio y para describir el personaje. Riera Llorca parece no tener en cuenta este aspecto al traducir el pasaje:

-' Espléndido! ¿Dónde se hospeda, scñor Swallow?'

-' De momento estoy en el Club de la Facultad mientras-'

-' Muy bien, muy bien, senõr Swallow. Usıed y yo tenemos que comer juntos uno de estos días.'

-' Me parece muy bien pero yo querría-'

-' Excelente. Y ahora que pienso en ello mi mujer y yo reunimos a algunos amigos para tomar unas copas el domingo, a eso de las cinco, ¿puede usted acompañarnos?'

-' Bueno, sí, muchas gracias' - dijo Swallow maquinalmente. 'Es decir, no, se trata...' Demasiado tarde, con un "Magnífico!" que puso fin a la conversación, Hogan colgó el aparato."

(pg.69-70)

El traductor aporta cuatro formas diferentes de exclamación en español para una misma forma en inglés: "Espléndido", "Muy bien, muy bien", "Excelente" y "Magnífico". Teniendo en cuenta que la repetición es en este caso intencionada, el traductor 
está traicionando en alguna medida el propósito del autor. Como consecuencia el efecto deseado no se consigue en la versión traducida del texto. El traductor debería primeramente haber buscado una forma exclamativa que se pudiera considerar idiosincrásica $\mathrm{y}$, seguidamente debería haber mantenido dicha forma a lo largo de todo el pasaje. Una posibilidad sería la utilización de la forma exclamativa "Estupendo".

No es este el único ejemplo que podemos encontrar de traducción "poco satisfactoria" en Intercambios en lo que se refiere a exclamaciones. El personaje del doctor O'Shea se convierte en el estereotipo de irlandés católico, sincero e ingenuo. Es en gran medida su particular empleo del lenguaje y, en concreto, su forma de exclamar lo que le define como tal: to start.'

' Mr. Zapp,' O'Shea panted, 'the devil take me if I can get my car

'God bless you, Mr.Zapp, you're a generous man.'

El idiolecto del doctor O'Shea es tan fácilmente identificable que uno de los personajes llega a "mimetizarse" con éste:

'Morris tried with some dificulty to imagine the likely reaction of O'Shea....Mother of God, he'd have a coronary on the spot.'

¿Cómo reacciona el traductor ante estos guiños que nos hace el autor a través de sus personajes? Simplemente omitiendo las exclamaciones. En la versión española el personaje de $\mathrm{O}$ 'Shea queda, pues, muy débilmente caracterizado, como se desprende de los siguientes ejemplos:

'Sr.Zapp' -dijo O'Shea, jadeante-, ' no consigo que mi coche arranque.'

'Muchas gracias, señor Zapp. Es usted un hombre generoso.'

La omisión se aplica también como procedimiento en el siguiente caso:

‘ El profesor trató de imaginarse la reacción de O’Shea ... Le daría un ataque cardíaco.'

Una vez más, el traductor debería, en primer lugar, reconocer la intención del autor al incluir esta serie de exclamaciones, lo que le hubiese llevado a reproducirlas en alguna 
medida en su propia versión del texto.

Junto a las exclamaciones, las palabras y expresiones consideradas como tabú constituyen un área de conflicto para el traductor, ya que la cultura juega un papel fundamental a la hora de determinar cuáles son las áreas de nuestro modo de vida que se consideran "prohibidas". Sin embargo, son muchos los puntos en común entre las culturas a la hora de delimitar estas áreas, algunas de ellas universales, más aún si hablamos de culturas occidentales como la hispana y la anglosajona.

A pesar de que se puede establecer una relación directa entre este tipo de expresiones y la dimensión cultural, hemos considerado el área de las expresiones tabú como perteneciente a la dimensión pragmática. El uso de tales expresiones por parte del hablante determina claramente, de la misma forma que lo hacen las exclamaciones, la actitud de dicho hablante. Son recursos utilizados por el autor que no solamente establecen el grado de formalidad o informalidad del texto, recursos estilísticos, en suma, sino que definen la posición ocupada por el hablante con respecto a su interlocutor y el efecto que debe producirse en éste.

Las expresiones tabú, los tacos, no se utilizan gratuitamente en el lenguaje literario. Una vez más, el proceso a seguir por el traductor ha de ser el de establecer cuál es la intención del autor al poner en boca de sus personajes este tipo de lenguaje e intentar conseguir un efecto equivalente en su taxto traducido.

En Changing Places el uso de este tipo de lenguaje establece el abrupto contraste entre dos personajes: Zapp, cuyo idiolecto está marcado por el uso y abuso de expresiones tabú, y Swallow, dueño de un lenguaje pulido y cuidado. De ese contraste tan marcado, de esas dos formas tan diferentes de expresar experiencias paralelas surge el humor, más aún cuando cada uno de ellos empieza a adoptar actitudes vitales del otro, mimetismo que viene expresado también en la adopción de un lenguaje diferente, el del otro.

Parece existir una tendencia casi natural en todo traductor a "suavizar" el lenguaje, a evitar expresiones malsonantes sustituyéndolas por eufemismos, quizá por consejo de la propia editorial y en relación directa con el tipo de lector al que va dirigido el texto. Evidencias de ello encontramos en Intercambios, donde muchas de estas expresiones se han visto suprimidas: "inviting ass" (pg.41) se transficre como "muchas invitaciones" (pg.46); "fuck" (pg.167) como "cópula" (pg. 167); "ball-breaker" (pg.236) como "mujer voraz" (pg.235), etc.

No por ello el traductor ha "cargado las tintas" en otras ocasiones intentando utilizar un mecanismo de compensación. Se debilita por tanto la caracterización de Zapp en el texto español y el lector de la versión traducida no puede percibir con tanta nitidez el cambio de personalidad experimentado por Swallow.

En definitiva y, una vez establecido cuál es el objetivo del traductor, buscar la equivalencia de efecto en su propio texto, hemos visto cómo, en el caso del lenguaje humorístico, el traductor debe llevar a cabo primeramente una labor de análisis que le permita encuadrar los dispositivos diseñados por el autor de acuerdo con la intencionalidad de éste. El traductor entonces tiene a su disposición una serie de procedimientos que le ayudan a la hora de procurar el mismo cfecto en su texto, procedimientos que en 
muchos casos deben ser diseñados individualmente y que apuntan al mecanismo de compensación como uno de los principios básicos de la traducción literaria.

\section{BIBLIOGRAFÍA}

BASSNETT-MCGUIRE, S. Translation studies, Methuen, London, 1980

BASSNETT-MCGUIRE, S.\& LEFEVERE, A. Translation, history and culture, Pinter publishers, London, 1990

BELL, R.T. Translation and translating: theory and practice, Logman, London, 1991

GOUANVIC, J.M. "Languages and culture in translation studies", TTR: Traduction,Terminologie, Rédaction, vol. 4, no. 1, Université Concordia, Montréal, 1991

GUTT, E.A. Translation and relevance, Basil Blackwell, Oxford, 1991

HOUSE, J. A model for translation quality assessment, Gunter Narr Verlag Tubingen, Tubingen, 1981

HATIM, B. \& MASON, I. Discourse and the translator, Logman, London, 1990

NASH, W. The Language of humour, Longman, London, 1985.

LODGE, D. Changing Places, Penguin, London, 1975.

LODGE, D. Intercambios, Versal, Barcelona, 1990.

SNELL-HORNBY, M. Translation studies: an Integrated approach, Benjamins, Amsterdam, 1988 